\title{
ARCHITECT-FRIENDLY CLIMATE ANALYSIS TOOL FOR BIOCLIMATIC DESIGN IN HOT HUMID CLIMATES
}

\author{
Shady Attia ${ }^{1}$ and Theo Lacombe ${ }^{1,2}$ \\ ${ }^{1}$ Sustainable Building Design Lab, Dept. UEE, Faculty of Applied Science, Université de Liège, \\ Belgium \\ ${ }^{2}$ EPF Graduate School of Engineering, Sceaux, France
}

\begin{abstract}
Climate analysis tools are complementary to building performance tools because designers need the ability to assess the potential effects of climate on specific building solutions. Although several existing climate analysis tools exist, many depend on static comfort models for fully space conditioned buildings, do not cater for free-running buildings in hot humid climates and require significant analytical expertise. Architects and urban planners need the ability to assess the potential of applying bioclimatic design strategies, in relation to adaptive comfort models within cities with hot humid climate, at relevant cities scales. Therefore, we present a climate analysis tool that can make climate analysis more accessible, practical and useful in hot climates. Firstly, we performed a climate zoning based on altitude, solar irradiation and dry bulb temperature. Secondly, we developed a bioclimatic analysis based on temperature and humidity levels. Focus group discussions involved 40 architects to assess the further develop the tool. In the paper, we show how the open-access tool provides building professionals a simplified method of climate zoning and a more convenient way of determining the best available thermal comfort models and suitable design solutions. This study contributes to research efforts that analyses and visualise climatic data for sustainable building design.
\end{abstract}

\section{Introduction}

Despite its importance being acknowledged in literature, so far, only limited attention has been paid to the ability of architects to understand climatic data plotted on psychrometric charts (Attia et al. 2019). The psychrometric chart is helpful in illustrating climatic data and thermal comfort conditions. It is also widely used by engineers and other professionals in the HVAC field. However, the problem remains that the psychrometric chart can be difficult to comprehend by architects and even engineering undergraduate students (Bhattacharya 2009). Most architects are confronted with the chart without understanding exactly what psychrometrics is Providing explanation of how it relates dry bulb temperature, relative humidity, dew point temperature, and absolute humidity does not make it easier to understand. Requiring significant analytical expertise to understand contribute to the controversial reputation of the psychrometric chart, which may be one of the reasons why the informative potential of such chart is largely unused in practice among architects.
Therefore, we present a climate analysis tool that can make climate analysis more accessible, practical and useful in hot climates. To tool was developed and tested with a focus on two Malagasy cities namely Antananarivo and Toamasina. We worked with weather data provided by both the National Meteorological Services (DGMM 2018) and extrapolated by Meteonorm (Meteotest, 2017). Then, we developed a new climate analysis tool linked to the two major cities of Madagascar, Antananarivo and Toamasina.

\section{Methodology}

We developed a conceptual framework that summarizes and visualizes our research methodology. As shown in Figure 1 our conceptual study framework is based on four axes that will be described in the following sections.

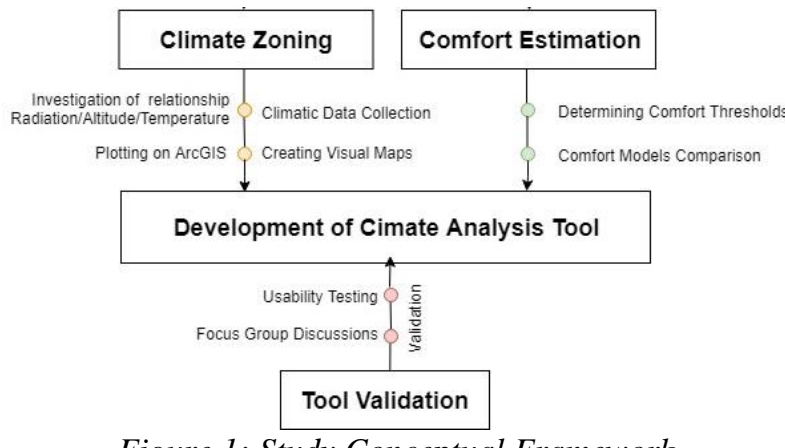

Figure 1; Study Conceptual Framework.

\section{Defining climatic zones}

Climate zones were defined by fixed boundaries that were established by the authors. Thus, we concentrated our effort on gathering new meteorological data in order to establish statistically representative climatic characterization for the whole island. We selected hourly measured data represented into TMY3 for nine local meteorological stations available between 1991 and 2008. The data were provided by the National Meteorological Service of Madagascar (DGMM, 2018) for ambient temperatures, humidity, precipitation, and wind speed in nine real Malagasy cities. Meteonorm (Meteotest, 2017) was used to extrapolate any missing data in the weather file's data set. Then, we pinpointed the location of those precedent local stations on the SolarGis interactive map, available online for temperature for solar radiation to acquire more data value sources on solar radiation and air temperature (Fick et al. 2017). We linked the data on the SolarGIS interactive map to data from the World GIS map 
for global solar radiation and mean monthly temperature provided by Fick and Hijmans (2017) for nine selected cities (Solargis, 2018). In parallel, we combined that information with the topography from the Shuttle Radar Topography Mission SRTM (Farr et al., 2007).

To define the climatic zones boundaries, we decided to consider only three parameters, namely: 1) solar radiation; 2) temperature; and 3 ) altitude based on the work of Prieto et al. (2009); Bristow et al. (1984) and Chandelet al. (2005). We selected those key climatic parameters because they are the most influential parameters for thermal comfort in hot climates. According to the study by Nguyen et al. (2012), the correlation and the regression coefficient between relative humidity and comfort temperature was found to be very low $\left(\right.$ Tcomf $\left.=0.073 \mathrm{RH}+22.77, \mathrm{R}^{2}=0.056\right)($ Nguyen et al., 2012), revealing a minor effect of relative humidity on thermal perception. Therefore, we excluded humidity to simplify our classification. The next step was to find a model that represents a causal relation between the three selected parameters. We reviewed the most highly cited studies that aimed to define the causal relationship between air temperature, solar radiation and altitude. We found the methodology proposed by Prieto et al. (2009) as the most accurate model that matches our climate characterization aims. This model has a similar or better accuracy for determining causal relationship than the models used by Bristow et al. (1984) and Chandel et al. (2005). Those two studies do not interpret exactly other factors that directly influence air temperature such as meteorological phenomenon. Prieto et al. (2009) proposed an equation with proper dimensions with two computed coefficients ( $a$ and $b$ ) from measurements that should reflect other climatologic parameters, such as precipitation, wind speed or relative humidity.

$$
a\left(\frac{z}{L}\right)^{b}=\left(\frac{G}{G_{0}}\right) /\left(\frac{\Delta T}{T_{r e f}}\right)^{0.5}
$$

where: $a$ and $b=$ computed coefficient for meteorological characteristics; $\mathrm{z}=$ altitude $(\mathrm{m}) ; \mathrm{L}=$ distance to sea $(\mathrm{Km})$; Tref $=$ temperature of reference is the monthly average minimum temperature ${ }^{\circ} \mathrm{C}$

Finally, by selecting the model of Prieto et al. (2009), we were able to establish the basis for our new climatic zoning based real data from Madagascar TMY3 weather files. The coefficients $a$ and $b$ mentioned in Equation 1 could be determined for each specific location and associated with a combination of solar radiation and air temperature value (Attia et al. 2019). The Jenk optimization method was used on this map to divide it in classes (Jenks, 1967) (see Figure 2d). It aims to minimize the difference inside a class and maximize the difference between them. This method would thus highlight the possible differences in climate. Each class would include one major type of climate.

In their study, Prieto et al. (2009) identified the parameters on the left side of the equation to calculate the parameters in the right side of the equation above. In our case, we reversed this approach. We already have all the values of the parameters on the right side of the equation. In fact, what we tried to calculate was the value of the left side of the equation. Fortunately, we had the $\mathrm{z}$ and $\mathrm{L}$ value on the left side of the equation, which makes the $a$ and $b$ factors the only unknown in our case. However, due to the difficulty to calculate the $a$ and $b$ factors separately we combined them together and calculate the combination of $\mathrm{a}$ and $\mathrm{b}$ factors. This calculation allowed us to resolve the equation through combining both parameters in one combined value.

\section{Mapping and visualization}

The next step after setting the mapping criteria was to map climatic zones of the island. We analysed our data using the software ArcGIS, which can generate customized maps according to the user's criteria (ESRI, 2017). For the generation of the maps we used the Kriging method of interpolation for which the interpolated values are modeled by a Gaussian process governed by prior covariance. We found the Kriging method gives the best linear unbiased prediction of the intermediate values. Then, we used three raster data sets for solar radiation, temperature and altitude. The resolution for solar radiation and temperature was $2.5 \min (\sim 4.5 \mathrm{~km})$ and $250 \mathrm{~m}$ for the altitude. Each raster data set included the mean value for each of the 12 months of a year so that we could derive an annual mean. Those mean values were then classified. We classified solar radiation into five categories for Madagascar.

- Category 1 (Csr1) includes values below 20.000 $\mathrm{kJ} / \mathrm{m}^{2} /$ days (about $230 \mathrm{~W} / \mathrm{m}^{2}$ )

- Category 2 (Csr2) includes values between 20.001 $\mathrm{kJ} / \mathrm{m}^{2} /$ days and $21.000 \mathrm{~kJ} / \mathrm{m}^{2} /$ days

- Category 3 (Csr3) includes values between 21.001 and $22.000 \mathrm{~kJ} / \mathrm{m}^{2} /$ day

- Category 4 (Csr4) includes values between 22.001 and $23.000 \mathrm{~kJ} / \mathrm{m}^{2} /$ day

- Category 5 (Csr5) includes values above 23.001 $\mathrm{kJ} / \mathrm{m}^{2} /$ days (about $280 \mathrm{~W} / \mathrm{m}^{2}$ ).

For temperature, we created five classes of values each ranging $4{ }^{\circ} \mathrm{C}$, starting at $15^{\circ} \mathrm{C}$ and below the annual mean temperature, and ending at $29{ }^{\circ} \mathrm{C}$ and above. We decided to determine a $250 \mathrm{~m}$ scale for the altitude from 0 to $1500 \mathrm{~m}$ and above. The final map represents the calculated coefficient ( $a$ and $b$ ) mentioned in Eq. 1. The coefficients are sorted with Jenks optimization method (Jenks, 1967). Once we created our classification classes we used the nine weather files and integrated them into our analyses. Weather data was transformed into data sets under the new classification and five key figures were created because of our analysis using ArcGIS. The figures map the key study parameters and cross them in order to create the new climate zone map.

\section{Estimating thermal comfort}

In order to select the fit-to-purpose comfort model in Antananarivo and Toamasina we compared several comfort models. We decided to compare different thermal comfort models on an hourly basis to have a better overview of thermal comfort requirement during the year 
in Madagascar. We compared Givoni's Model (1992), ASHRAE's (2017) model and EN 16798's (2017) models based on the formulas found in each standard. By reviewing different models and their different ranges and thresholds, we were able to suggest and recommend existing comfort models to both cities (Carlucci et al. 2018). We avoided steady-state comfort models because they neglect the effect of humidity adaptation of people living in a hot humid climate.

\section{Tool development}

After selecting a comfort model, we decided to visualize climatic data in a simple bioclimatic chart developed by DeKay and Brown (2014). DeKay and Brown's graphical illustration redrew Givoni's bioclimatic chart using the structure of Olgyay's chart (1992) in a simple way. They implemented Milne-Givoni's different and diverse strategy zones in Olgyay's rectangular chart. In this chart, five cooling strategies and two heating strategies are included. In the present study, we redrew the proposed bioclimatic chart of DeKay and Brown more precisely (DeKay \& Brown, 2014) to investigate its potential, as shown in the results. We wanted to avoid the complexity of the psychrometric chart and make a simple tool for architects during the early design.

\section{Usability testing}

Similar to the work of Attia et al. (2009 and 2012), our research methodology created a randomized, controlled, architects-based usability testing for which architects from Madagascar were recruited. We performed a usability testing with 40 architects and urban planners to assess the usability of the tool and its interface. Usability testing has been carried out in February 2018 and summer 2018 while simple paper-based questionnaires were distributed. The system usability scale was used to highlight the weakness and strength of the tool. The usability testing was useful to compare our proposed climate analysis chart to the psychrometric chart. We hypothesized that a comparative usability study might elicit responses that are more critical since the participants had a chance to compare the two visualisations side-byside during the same session. This enabled the updating of the tool's interface and the psychrometric chart's representation to be avoided and replaced with simple graphs.

\section{Results}

In this section, we present the study outcomes regarding the climatic zoning, climate analysis tool, comfort model recommendations, and bioclimatic design strategies. The final tool and detailed study results can be found in the publication of Attia et al. 2018 and 2019.

\section{Climate zoning of Madagascar}

Key figures were created using ArcGIS. The figures map the key study parameters and cross them to achieve a novel climate zone map. The first map represents the altitude as shown in Figure 4. The altitude has been considered using SRTM data for Madagascar's topography.
Figure 2a represents the solar radiation map with annual mean values. We see a gradient variation moving from the eastern coast to the western coast. The maximum value is $24,071 \mathrm{~kJ} / \mathrm{m}^{2} /$ day and the minimum value is 19,412 $\mathrm{kJ} / \mathrm{m}^{2} /$ day. Figure $2 \mathrm{~b}$ represents the annual mean temperature zones. The highlands have lower temperature mean 'values than the coastal regions. The
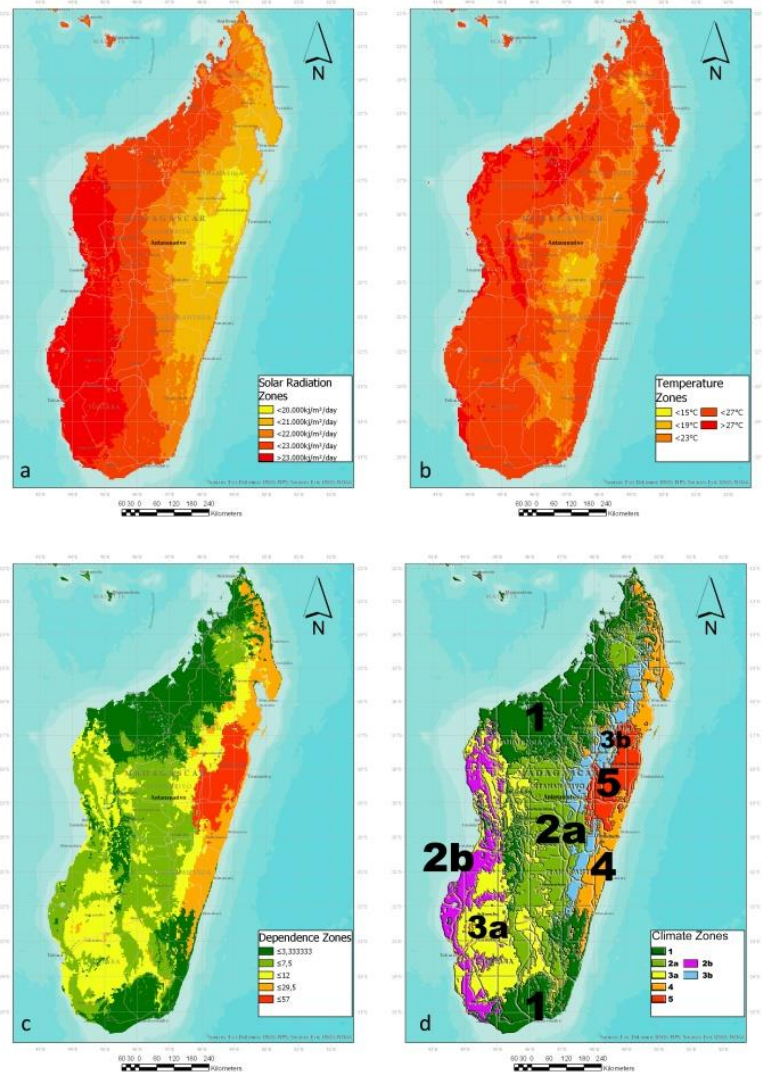

Figure 2; a: Solar Radiation Classified Map; b; Dry bulb Temperature Classified Map; c; Dependence Map; d; New Climate Zoning Map for Madagascar.

western regions present a slightly higher average temperature, especially in the north-west region. Most of the island has an average temperature of between $23{ }^{\circ} \mathrm{C}$ and $27{ }^{\circ} \mathrm{C}$. Figure $2 \mathrm{c}$ shows the results of applying Eq. 1, which was described earlier. The map represents the calculated coefficient ( $a$ and $\underline{b}$ ) values sorted with Jenks optimization method (Jenks, 1967). We combined them together and calculate the combination of $a$ and $b$ factors. This calculation allowed us to resolve the equation through combing both parameters in one combined value. The advantage of this approach is that we managed to provide a simple and comprehensive analysis for the climate to create the climatic zones illustrated in Figure 2c. Without this simplification, we could never have managed to come up with our climate analysis. Moreover, we found our approach unique and valid. By simplifying Prieto's equation, we believe our climate analysis can be reproducible and transferable to future climate zoning analysis in other regions in hot climates. 
That way we ensure that classes are as consistent as possible and reflect true differences of climates. A higher coefficient value (red) means that solar radiations have less influence on temperature. Thus, other weather parameters weigh more in the temperature variation. A lower value means solar radiations have a higher impact on ambient temperature. We can see that the eastern coast distinguishes itself from the rest of the island with higher values. The extreme north and south areas present a high coefficient value between solar radiation and temperature. High plateaus in the central region present relatively high coefficient values but also distinguish themselves from the rest of the island. The south-west regions present a moderate relation. The implementation of altitude here permits the considering of the decreasing gradient of temperature in relation to altitude. Finally, the climate map shown in Figure 2d takes the coefficient values as well as air temperature, solar radiation and altitude to determine climate zones. Seven climate zones can be identified. Table 1 shows the different characteristics of each climate zone in terms of temperature range and solar radiation average. Antananarivo is in Zone $3 \mathrm{~b}$ and Toamasina in Zone 4.

\section{Thermal comfort models}

By reviewing different models and their different ranges and thresholds we were able to suggest and recommend existing comfort models to both cities. Humidity was a crucial factor to select a comfort model because both cities reach $100 \%$ relative humidity during several hours in the year. Finally, we selected the ASHRAE 552017 (adaptive model) because it can tolerate very high ranges of humidity and temperatures. We need to remind the reader that Madagascar is among the 25 nations with the least wealth. Therefore, selecting a comfort model with a wide range coupled with passive climate responsive strategies can be effective from a socio-economic perspective.

Table 1; Climate characteristics

\begin{tabular}{|c|c|c|}
\hline Zones & Characteristics & Locations \\
\hline 1 & $\begin{array}{c}\text { Low altitude } \\
>23^{\circ} \mathrm{C} \text { average } \\
22-23000 \mathrm{~kJ} / \mathrm{m}^{2} / \text { day }\end{array}$ & $\begin{array}{l}\text { North and South } \\
\text { plains }\end{array}$ \\
\hline $2 \mathrm{a}$ & $\begin{array}{c}\text { High altitude } \\
<15-23^{\circ} \mathrm{C} \text { average } \\
21-22000 \mathrm{~kJ} / \mathrm{m}^{2} / \text { day }\end{array}$ & $\begin{array}{c}\text { Central } \\
\text { Highlands }\end{array}$ \\
\hline & Low altitude & \\
\hline $2 \mathrm{~b}$ & $23-27^{\circ} \mathrm{C}$ average & \\
\hline & $>23000 \mathrm{~kJ} / \mathrm{m}^{2} /$ day & $\begin{array}{l}\text { South-West } \\
\text { Coast }\end{array}$ \\
\hline $3 a$ & $\begin{array}{l}\text { Medium altitude } \\
<27^{\circ} \mathrm{C} \text { average } \\
>23.000 \mathrm{~kJ}\end{array}$ & South-West \\
\hline $3 b$ & $\begin{array}{l}\text { Medium altitude } \\
<23^{\circ} \mathrm{C} \text { average } \\
<21000 \mathrm{~kJ} / \mathrm{m}^{2} / \text { day }\end{array}$ & East Highlands \\
\hline 4 & Low altitude & East Coast \\
\hline
\end{tabular}

\begin{tabular}{ccc} 
& $23-27^{\circ} \mathrm{C}$ average & \\
& $<21000 \mathrm{~kJ} / \mathrm{m}^{2} /$ day & \\
\hline 5 & Low to medium altitude & East Coast till \\
& $>23-27^{\circ} \mathrm{C}$ average & Highlands \\
& $<20000 \mathrm{~kJ} / \mathrm{m}^{2} /$ day & \\
\hline
\end{tabular}

\section{Climate analysis tool}

The climate analysis tool is an open access tool programmed in Visual Basic (VB). The tool is available online by following this reference link (Attia \& Lacombe, 2018 and Roshan et al. 2019). This representation was inspired by the work of DeKay and Brown (2014), as shown in Figure 3. Table 2 shows the results presented in Figure 3 , in a tabular format. The table enables the quantification of the potential of the corresponding passive design strategies of both cities.

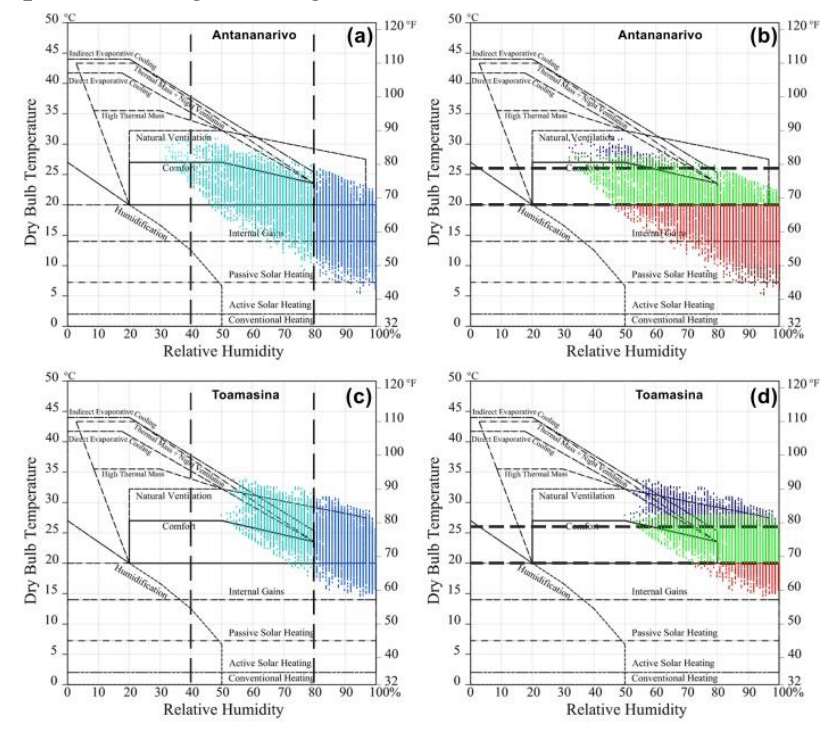

Figure 3; A plot of the hourly humidity and temperature data points, a: humidity thresholds (Antananarivo); $b$ temperature thresholds (Antananarivo); c humidity thresholds (Toamasina); d temperature thresholds (Toamasina).

Table 2; potential passive cooling and heating strategies for both cities

\begin{tabular}{|c|c|c|c|}
\hline Strat. & $\begin{array}{c}\text { Bioclimatic Chart Cooling and } \\
\text { Heating Strategies }\end{array}$ & Ant. & Toa. \\
\hline S1 & Conventional Heating & $0 \%$ & $0 \%$ \\
\hline $\mathrm{S} 2$ & $\begin{array}{l}\text { Conventional } \\
\text { Humidification }\end{array}$ & $0 \%$ & $0 \%$ \\
\hline S3 & $\begin{array}{l}\text { Passive Solar } \\
\text { Humidification }\end{array}$ & $0 \%$ & $0 \%$ \\
\hline S4 & Internal Gains + Humidification & $0 \%$ & $0 \%$ \\
\hline S5 & Humidification & $0 \%$ & $0 \%$ \\
\hline S6 & Passive Solar Heating & $18.5 \%$ & $0 \%$ \\
\hline S7 & Comfort & $22 \%$ & $45 \%$ \\
\hline S8 & Natural Ventilation & $12 \%$ & $15 \%$ \\
\hline S9 & Dehumidification & $55 \%$ & $81 \%$ \\
\hline S10 & $\begin{array}{l}\text { Natural Ventilation }+ \text { High } \\
\text { Thermal Mass }+ \text { Night Ventilation }\end{array}$ & $0 \%$ & $0 \%$ \\
\hline
\end{tabular}




\begin{tabular}{|l|l|c|c|}
\hline & $\begin{array}{l}+ \text { Direct \& Indirect Evaporative } \\
\text { Cooling }\end{array}$ & & \\
\hline S11 & $\begin{array}{l}\text { Direct \& Indirect Evaporative } \\
\text { Cooling + Thermal Mass + Night } \\
\text { Ventilation }\end{array}$ & $0 \%$ & $0 \%$ \\
\hline S12 & $\begin{array}{l}\text { Direct \& Indirect Evaporative } \\
\text { Cooling }\end{array}$ & $0 \%$ & $0 \%$ \\
\hline S13 & $\begin{array}{l}\text { Air Conditioning (Cooling } \\
\text { requirements) }\end{array}$ & $12 \%$ & $26 \%$ \\
\hline
\end{tabular}

We also included in the tool a comfort models comparison feature, which enables visualization of the differences of applying different comfort models to the same weather file. Figure 4 illustrates the outdoor air temperature value for a TMY for the two case studies. Antananarivo' is heating-dominated during winter (between May and September). There is a discrepancy between the running mean temperature in the winter and the acceptable comfort conditions indoors. In light green, there are days when the outdoor reference temperature is out of the prescribed temperature domain specified by ASHRAE 55 's adaptive comfort lower limit.

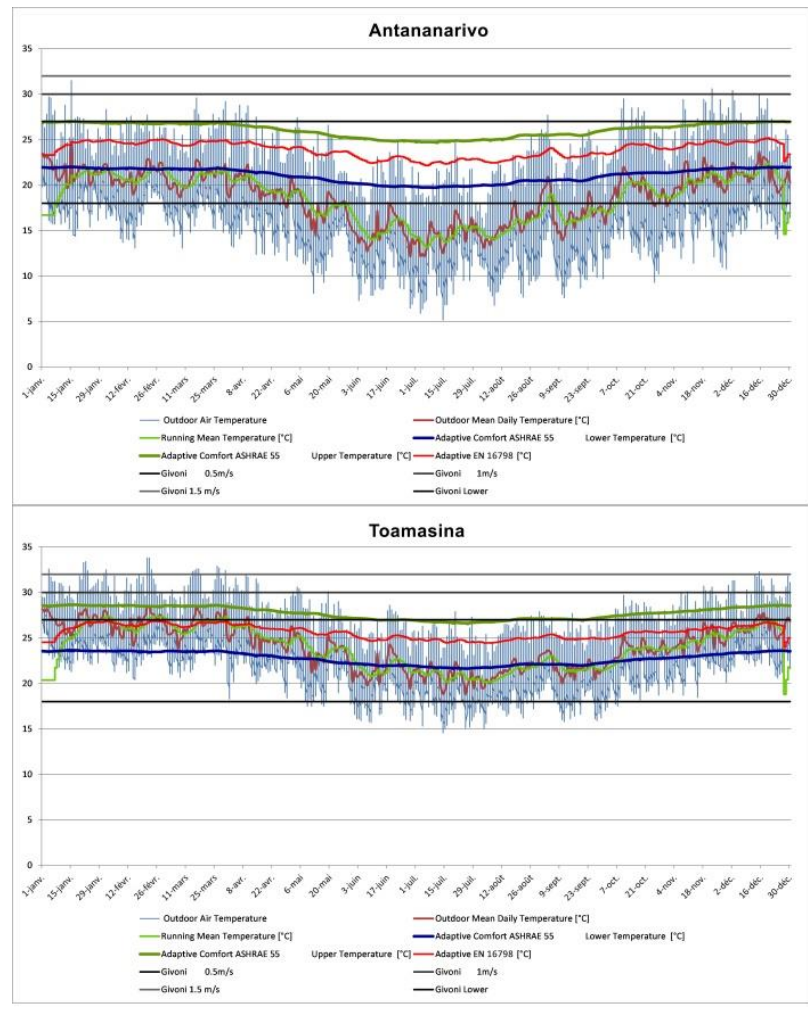

Figure 4; Comfort Models Comparison for Antananarivo and Toamasina.

We can observe that Antananarivo does not have a cooling period but some hours during summer that are above the thermal comfort zone limits. Thus, the most effective bioclimatic design strategies are dehumidification (55\%) and passive solar heating (20\%). This matches the case of Antananarivo, which is located at an altitude of $1300 \mathrm{~m}$ above sea level. In the case of Antananarivo, we recommend using the ASHRAE 55 adaptive comfort model because it establishes a range of humidity levels that are considered comfortable by $80 \%$ or more. On the other hand, EN 16798 standard sets an upper limit of $50 \%$ humidity, which is not feasible for free-running or mixed buildings in Madagascar, where people are more adapted to higher humidity values.

For Toamasina we can confirm that average temperatures are much higher than Antananarivo during the summer. Thus, the most effective bioclimatic design strategy is dehumidification $(80 \%)$ and natural ventilation $(15 \%)$. The temperatures in winter are warm enough to avoid active heating and rely on passive design strategies. During the summer period, the high temperature can cause discomfort in the absence of proper ventilation. Based on the focus group discussion with local experts from Toamasina, they considered that the overheating risk is high, and the residential buildings tend to be coolingdominated. Therefore, we recommend the use of the ASHRAE adaptive comfort model, which, similarly to Antananarivo, can tolerate higher humidity limits.

\section{Climate tool validation}

The final step of the research was to validate the tool's output results and elaborate on the recommendations' description based on practical experience of local stakeholders. After analysing the weather files of Antananarivo and Toamasina using the Climate Tool, stakeholders were asked to validate the suggested strategies. Their input was incorporated in the final version of Table 2 .

\section{Focus group discussions}

The focus group discussions allowed the tool's sensitivity to be evaluated with reference to the local context of both cities. Experts agreed with the analysis provided by the tool at the first stage of discussion. The tool can quantify the effect of passive heating and cooling strategies as shown in Figure 3a. The tool indicates that $43 \%$ of the annual hours (8760) fall within the acceptable humidity limits $(40 \%-80 \%)$, and more than $55 \%$ of the annual hours require dehumidification. As shown in Figure 3b, Antananarivo has $22 \%$ of its hours in the temperature comfort zone, the majority of the year it would need passive heating (18.5) coupled with high internal heat gains (35.5). As shown in Figure 3c, Toamasina presents an extreme level of average humidity with more than $81 \%$ of the year that is above $80 \%$ of relative humidity. As shown in Figure $3 \mathrm{~d}$, the temperature average of Toamasina is $24{ }^{\circ} \mathrm{C}$ but the majority of the year it still falls in the comfort zone; $45 \%$ of the hours are within the tool's thermal comfort boundaries.

At the second stage of discussion experts developed more specific recommendations, shown in Table 2, that aim at improving thermal comfort and indoor air quality in buildings in both investigated cities. The experts reached consensus on the recommendations presented in

\section{Table 2.}

\section{Usability testing}

To test the user interface and the tool's friendliness, usability testing took place in February 2018 with 40 users 
comprising architects and urban planners. The usability testing included two test types.

The first was a usability testing that measured a task's success. The aim was to measure how effectively users are able to understand the climate characteristics of two cities (round 1: Ho Chi Minh City and round 2: Ha Noi) in Vietnam and identify the top three relevant climate responsive strategies using Dekay and Brown's chart versus the psychrometric chart. We explicitly selected two cities in Vietnam to make sure participants would not rely on their personal experience with Malagasy cities. We identified the top three relevant climate responsive strategies for both cities based on the work of Nguyen and Reiter (2014). The level of success was compared as shown in Figure 5. The figure shows that the use of Dekay and Brown's chart had a higher success rate compared to using the psychrometric chart. The successful rate of climate analysis was increased by at least $50 \%$ by the 40 architects and urban planners. During the second round of performing climate analysis the successful rate was greater $(55 \%)$ with $91 \%$ of participants succeeding to identify the climate responsive strategies of Ha Noi.

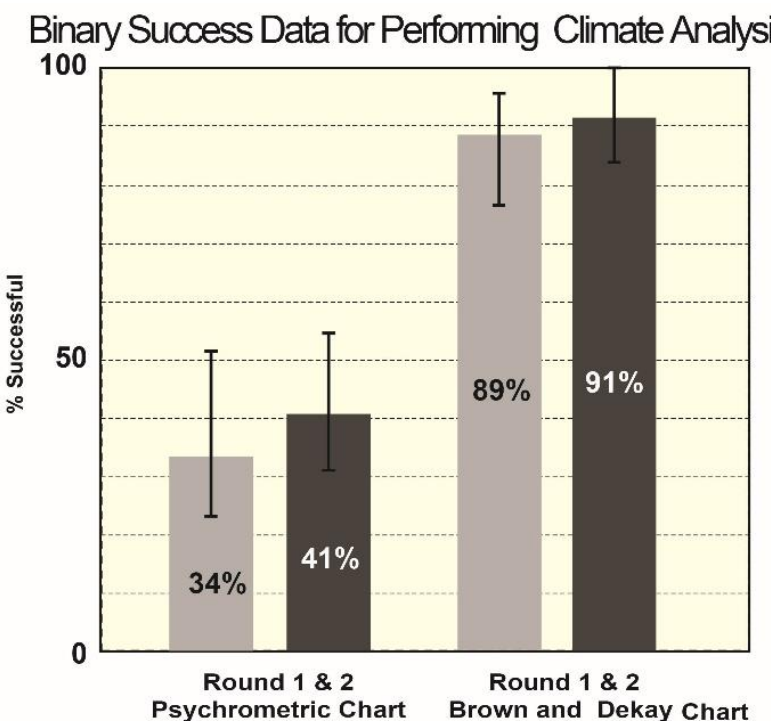

Figure 5; Binary success data for performing climate analysis

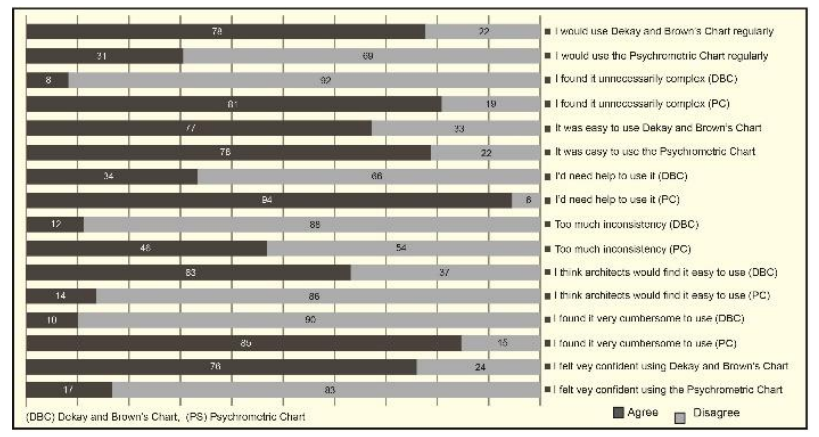

Figure 6; Usability testing of the psychrometric chart and Dekay and Brown's chart using system usability scale.
The second test was a satisfaction simple paper-based usability questionnaire. System Usability Scale (SUS), as defined by the standard, was used to enhance and validate the tool (ISO, 9241 and Attia et al .2012). To guarantee the internal validity of the test a set of eight ordinary (predefined) SUS questions were used. The analysis of the responses was based on the reporting framework (ISO, 9241). A paper-based survey was conducted using Likert scale. Users have ranging from 1 to 5. (1='strongly disagree' - 5=strongly agree'). Scores

were added and the total was multiplied by 2.5 . A mean score was computed out of the chosen responses with a range between 0 and 100 . The highest the score the more usable the website is. Any value around 60 and above is considered as good usability. As shown in Figure 6, Brown and Dekay's chart scored a very good usability for the eight questions, however, the psychrometric chart use was not satisfactory. Participants were interviewed after conducting the usability testing to follow up and get a valuable understanding of the psychrometric chart's limitations.

Overall, the reactions were particularly positive regarding the tool's simplicity and effectiveness. Participants clearly preferred DeKay and Brown's figure (Figure 3) for climate data representation (DeKay \& Brown, 2014). These clear visualisation preferences are interesting and in line with previous findings found in literature (Roshan et al., 2017). Within a few minutes of being introduced to our tool, participants got excited about the tool as it could clearly foresee how the visualisation would facilitate their understanding of climate conditions and required design strategies that can be effective in selected climate. Some participants asked about the availability of the tool, as they wanted to use it in their practice. From the analysis, it emerged that there is great potential for the interface. From the open questions and post-testing interviews, users appreciated the comfort model's comparison graph. Respondents were also particularly enthusiastic about the quantification of the effect of passive heating and cooling strategies, shown in Table 2. However, the post-usability testing interviews revealed other limitations. For example, many users indicated their need to translate the suggested passive strategies into market-available building solutions and products rather theoretical climateresponsive guidelines.

\section{Discussion}

In this study, we used recent TMY files and a simple chart to create a user-friendly tool for climatic analysis and provide generic bioclimatic design recommendations. The tool represents and visualizes climate data, enabling users to understand the comfort requirements for the largest two cities of Madagascar. We designed the tools with architects in mind and the FGD confirmed that the tool is easy to use and allows understanding the climate in both cities as illustrated in Figure 4. Compared to the psychrometric chart our tool, which is based on the graphs of DeKay and Brown (2014) allows users to straight read the graphs and understand the climatic conditions. Without any background in engineering, physics, or 
meteorology, architects succeeded to understand the nature if the weather and identify the most fit-to-climate bioclimatic design strategies that need to be applied for the design in both cities.

Despite the work of Nematchouaet al. (2017), which focuses mainly on comfort perception in educational buildings in Madagascar, we are not aware of any study that has addressed thermal comfort for residential buildings during the early design stages. Also, participants generally found the climate analysis visualisation informative. Compared to the psychrometric chart participants showed a strong preference for our tool and the results revealed the importance of showing climate data to architects in the way they can understand.

Therefore, we confirm that the tool can be used in other countries, and in hot climate regions. On the other hand, there are some important limitations that require discussing. The temperature and solar radiation for the climatic zoning (Figure 2) have been extrapolated in some places due to lack of data; we need to be careful about the liability of the extrapolation method used in our study. The data used for mapping is based on yearly averages, thus the solar-radiation value and temperature range may vary according to the month and the season. Only two variables and one constant were selected for the mapping (solar radiation, temperature and altitude), while several additional parameters, such as humidity, could have influenced the climate classification and made it more accurate. Also, the nine analysed weather files are not well distributed at Madagascar's level. In our case, we exhausted all available resources combining recent data sets from weather station and satellite maps.

Based on our experience during the focus group discussions, we wish to expand the pool of architects and urban planners to confirm participant's statements on the beneficial use of the tool. One can imagine other visualisations, specifically designed architects needs for climate data analysis and visualisation. More work is necessary to show generalizability of our climate analysis visualisation chart for architects, urban planners and professionals in other building design domains.

\section{Conclusion}

This paper proposes a climatic zoning of Madagascar Island based on yearly solar radiation and temperature average. We realized the map with the software ArcGIS as well as WorldClim data for the best resolution. We used TMY3 data from the National Meteorological Service and Weather stations and developed a new climate analysis tool based on a simple chart that allows weather files to be analysed and provided various bioclimatic design recommendations.

Our climatic zoning allowed us to place Antananarivo in Zone $3 \mathrm{~b}$ and Toamasina in Zone 4. This enables a quick determination of a passive solar design and the evaluation of their (passive design measures) potential application for building designs in these major cities of Madagascar. Additionally, we developed a climate analysis application based on Visual Basics Language which can be used to compare the ASHRAE-55 steady-state and adaptive models, the EN 16798 steady state model, and the Givoni model in the form of annual temperature profiles (see Figure 4). The tool also represents temperature in terms of relative humidity with boundaries, where comfort boundaries have been defined for a hot humid climate. In the case of our tool, the temperature ranges from $20^{\circ} \mathrm{C}$ to $26{ }^{\circ} \mathrm{C}$ and relative humidity from $40 \%$ to $80 \%$.

Our climate analysis tool was found to promote and inform decision-making for bioclimatic design in Antananarivo and Toamasina during the predesign stage. Participants who used the Climate Analysis Tool succeeded to perform and climate analysis and identify key passive design measures with the help of Dekay and Brown's chart. The 40 architects and urban planners were significantly satisfied $(91 \%)$ with the use of our tool and appreciated it is easy to understand climate data visualisation. Our tool increases the knowledge about the climate specific characteristics of cities in hot-humid climates. Architects and urban planners who used the tool reported a better understanding of the climate and appreciated the guided approach for sustainable building design. We consider this tool as a starting point for the development of a widely usable comfort model and design recommendations in Madagascar.

\section{Acknowledgement}

This research was funded by the EU Erasmus+ Grant part of MADEEHI project. We would like to acknowledge the Sustainable Building Design Lab for the use of data sets in this research and the Institute of Technology (IST) in Antananarivo. We would like to thank all participants of the IST who helped to assess the tool through usability testing and focus group discussions. The authors gratefully acknowledge MADEEHI project for providing excellent research networking.

\section{References}

ASHRAE (2017). ANSI/ ASHRAE standard 55-2017 thermal environmental conditions for human occupancy. American Society of Heating, Refrigerating and Air-Conditioning Engineers, Inc.

Attia, S., Lacombe, T., Rakotondramiarana, H. T., Garde, F., \& Roshan, G. R. (2019). Analysis Tool for Bioclimatic Design Strategies in Hot Humid Climates. Sustainable Cities and Society, Vol.45, February 2019, p 88-24, 10.1016/j.scs.2018.11.025.

Attia, S., \& Lacombe, T. (2018). Climate tool V1.0.0.xlx. Available https://orbi.uliege.be/handle/2268/227384.

Attia, S., Gratia, E., De Herde, A., \& Hensen, J. L. (2012). Simulation-based decision support tool for early stages of zero-energy building design. Energy and Buildings, 49, 2-15.

Attia, S., Beltrán, L., De Herde, A., \& Hensen, J. (2009). "Architect friendly": A comparison of ten different building performance simulation tools. In Proceedings of 11th International Building Performance Simulation Association (IBPSA). 
Autodesk (2018). Ecotect weather tool, version 8.

Bhattacharya, Y., \& Milne, M. (2009). Psychrometric chart tutorial: A tool for understanding human thermal comfort conditions. 38th American Solar Energy Society Conference, 11-16.

Bristow, K. L., \& Campbell, G. S. (1984). On the relationship between incoming solar radiation and daily maximum and minimum temperature. Agricultural and Forest Meteorology, 31(2), 159-166.

Carlucci, S., Bai, L., de Dear, R., \& Yang, L. (2018). Review of adaptive thermal comfort models in built environmental regulatory documents. Building and Environment.

Chandel, S. S., Aggarwal, R. K., \& Pandey, A. N. (2005). New correlation to estimate global solar radiation on horizontal surfaces using sunshine hour and temperature data for indian sites. Journal of Solar Energy Engineering, 127(3), 417.

DeKay, M., \& Brown, G. Z. (2014). Sun, wind, and light: Architectural design strategies. John Wiley \& Sons.

DGMM (2018). Direction générale de la Météorologique De Madagascar.

EN 16798 (2017). Indoor environm ental input parameters for design and assessm ent of energy performance of buildings addressing indoor air quality, thermal environment, lighting and acoustics. EU for Standardization.

ESRI, (2019) Environmental Systems Research Institute. ArcGIS desktop 10.5.1.

Farr, T. G., et al. (2007). The shuttle radar topography mission. Reviews of Geophysics (Washington, DC: 1985, 45, RG2004.

Fick, S. E., \& Hijmans, R. J. (2017). WorldClim 2: New $1-\mathrm{km}$ spatial resolution climate surfaces for global land areas. International Journal of Climatology.

Givoni, B. (1992). Comfort, climate analysis and building design guidelines. Energy and Buildings, 18(1), 1123.

Jenks, G. F. (1967). The data model concept in statistical mapping. International yearbook of cartography, 7 , 186-190.

Meteotest (2017). Meteonorm v7.2.

Milne, M., Liggett, R., \& Al-Shaali, R. (2007). Climate consultant 3.0: A tool for visualizing building energy implications of climates. Proceedings of the Solar Conference, Vol. 1, 466.

Nematchoua, M. K., Ricciardi, P., \& Buratti, C. (2017). Adaptive approach of thermal comfort and correlation between experimental data and mathematical model in some schools and traditional buildings of Madagascar under natural ventilation. Sustainable Cities and Society.
Nguyen, A. T., Singh, M. K., \& Reiter, S. (2012). An adaptive thermal comfort model for hot humid South East Asia. Building and Environment, 56, 291-300.

Nguyen, A. T., \& Reiter, S. (2014). A climate analysis tool for passive heating and cooling strategies in hot humid climate based on Typical Meteorological Year data sets. Energy and Buildings, 68, 756-763.

Prieto, J. I., Martinez-Garcia, J. C., \& Garcia, D. (2009). Correlation between global solar irradiation and air temperature in Asturias, Spain. Solar Energy, 83(7), 1076-1085.

Roshan, G. R., Farrokhzad, M., \& Attia, S. (2017). Defining thermal comfort boundaries for heating and cooling demand estimation in Iran's urban settlements. Building and Environment, 121, 168189.

Roshan, Gh.R., Oji, R., Attia,S. (2019) Projecting the impact of climate change on design recommendations for residential buildings in Iran, Building and Environment, in press.

Solargis (2018). Solargis IMAPS, interactive solar potential maps, Accessed: 28.06.2019, Available from: https://solargis.com/products/imaps/overview/ 